\title{
National identification as a function of perceived social control: A subjective group dynamics analysis
}

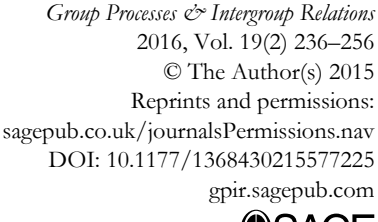

@SAGE

\author{
Isabel R. Pinto, ${ }^{1,2}$ José M. Marques, ${ }^{1,2}$ and Dario Paez ${ }^{3}$
}

\begin{abstract}
Based on subjective group dynamics theory (SGDT; e.g., Marques, Paez, \& Abrams, 1998), we examine the effects of a group's ability to effectively control its deviant members on participants' ingroup identification. In Studies 1 and $2(N=79$ and $N=173)$ participants were informed that the ingroup (vs. outgroup) dealt with deviant occurrences in an effective (vs. ineffective) way. As predicted, induced ingroup effectiveness generated higher ingroup identification, trust in the ingroup's social control system, and more positive emotional climate, whereas induced ingroup ineffectiveness generated more negative emotional climate or anomie and weaker ingroup identification as compared to outgroup conditions. In Study $3(N=115)$, perceived ingroup effectiveness predicted ingroup identification, via emotional climate, ingroup anomie, confidence in the group's social control system, and ingroup emotions. We discuss the results in light of SGDT and the role of perceived ingroup social control in promoting ingroup identification.
\end{abstract}

\section{Keywords}

perceived social control, social identification, subjective group dynamics

Paper received 20 March 2014; revised version accepted 12 February 2015.

In a recent address to the media, European Commissioner Cecilia Malmstrom used the term "breathtaking" to qualify corruption in Europe. She pointed out that whereas some EU countries have adopted sound anticorruption measures, others have been less than effective in that endeavor. Simultaneously, Commissioner Malmstrom reported that about $75 \%$ of Europeans consider that corruption is widespread, and about $50 \%$ consider that it is increasing ("Corruption across EU," 2014). Recent investigation has focused on the way people represent "corruption" as a social object (e.g., Davis, Camp, \& Coleman, 2004; De Sousa,
2008; Heidenheimer, 2002; Poeschl \& Ribeiro, in press), but did not consider the impact of the effectiveness of countries' anticorruption measures on their citizens' beliefs and expectations

\footnotetext{
${ }^{1}$ University of Porto, Portugal

${ }^{2}$ Institute of Social Sciences - University of Lisbon, Lisbon, Portugal

${ }^{3}$ University of Basque Country, Spain

Corresponding author:

Isabel R. Pinto, Faculty of Psychology and Educational

Sciences, University of Porto, Rua Alfredo Allen, 4200-13,

Porto, Portugal.

Email: ipinto@fpce.up.pt
} 
about, and identification with, their national group. We propose that such (in)effectiveness affects individuals' emotions about the ingroup, trust in the group's normative system, and perceived emotional climate which, in turn, mediate individuals' social identification.

Deviance and the responses it triggers are important components of social life. As was recognized both by earlier (e.g., Becker, 1963; Durkheim, 1982, 1997; Merton, 1938, 1968; Simmel, 1955) and by contemporary scholars (e.g., Ben-Yehuda, 1985; Clinard \& Meier, 2004), deviance may harm group cohesiveness and encourage anomie, but it may also allow normative group members to express their disapproval, either overtly or tacitly. When this is the case, deviance ultimately increases group members' awareness of, and compliance with, the group's normative system, thus boosting the group's normative cohesiveness (e.g., Erikson, 1964; Garland, 1996; Gibbs, 1977; Hamilton \& Rauma, 1995; Harris \& Hill, 1982; Inverarity, 1980).

\section{Subjective Group Dynamics Theory (SGDT)}

Partly based on the aforementioned ideas, Marques, Paez, et al. (1998; see also Marques, Abrams, Paez, \& Taboada, 1998; Marques \& Paez, 1994; Pinto, Marques, Levine, \& Abrams, 2010) proposed subjective group dynamics theory (SGDT). SGDT establishes a parallel between judgments of deviant ingroup members in large social categories, or "common-identity" groups (cf. Prentice, Miller, \& Lightdale, 1994), and social pressures exerted upon deviants in face-to-face groups. Another foundation of SGDT is the social identification approach, including social identity theory (e.g., Tajfel, 1978) and self-categorization theory (e.g., Turner, Hogg, Oakes, Reicher, \& Wetherell, 1987; cf. Hogg \& Abrams, 1988), with the core assumption that people define themselves and others in terms of their respective inclusions in meaningful, distinctive, social categories (Turner, 1975). Self-inclusion in a category can often generate an attitude of ingroup favoritism, reflected by preferences for ingroup members, performances, and products, as compared to similar occurrences in relevant outgroups. This would ensure the ingroup's comparative superiority, or positive social identity (Tajfel, 1978; Turner, 1981). In that case, according to this view, social identification should primarily be an antecedent of group-related beliefs, perceptions, and judgments.

SGDT claims that social identification may be both an antecedent and a function of grouprelated beliefs, perceptions, and judgments, specifically regarding how the ingroup responds to deviance (cf. Marques, Paez, et al., 1998). As a case in point, differentiation between normative and deviant ingroup members leads people to reinforce their identification with the group. This occurs because differentiation between normative and deviant members increases perceived intragroup consensus around normative standards that legitimate positive ingroup differentiation. This idea is supported by previous evidence. For example, Marques, Abrams, and Serôdio (2001, Experiments 1 and 2) showed that participants differentiated more strongly between normative and deviant ingroup members when the ingroup lacked consensus regarding a prescriptive norm that legitimated belief in the ingroup's superiority. Also Marques, Abrams, et al. (1998), Marques, Robalo, and Rocha (1992), and, more recently, Hutchinson and Abrams (2003) found that differentiation between normative and deviant ingroup members is associated with a more positive evaluation of the ingroup than the outgroup as wholes. Although these and other studies (e.g., Hutchison \& Abrams 2003; Hutchison, Abrams, Gutierrez, \& Viki, 2008; see also, Branscombe, Wann, Noel, \& Coleman, 1993) have traditionally considered ingroup identification to moderate evaluative differentiation between normative and deviant ingroup members, we believe the group's ability to respond to deviance (e.g., by derogating or by punishing its deviant members) should also be an important mechanism through which individuals increase their identification with the ingroup (Marques, Abrams, et al., 1998; Pinto et al., 2010) 


\section{The Current Studies}

SGDT proposes that individuals' perception that the group is able to uphold its normative standards affects ingroup identification. Socialization pressures, derogation, or punishment of ingroup deviants (Levine, 1989; Orcutt, 1973; Pinto et al., 2010) should restore group standards and legitimate group members' claim for a positive social identity. In turn, if deviance goes unpunished, the standards that legitimate a positive social identity appear jeopardized in group members' eyes.

We propose that the strength of people's social identification is not only an antecedent of individuals' normative judgments and behavior and correlated emotional beliefs about deviance, but that it may also be a function of those judgments and beliefs. We hypothesize that such strength should increase with the perception that the group is able to sustain its standards in the face of deviance. Ability to sustain ingroup standards in such conditions should trigger positive ingroup emotions, trust in the group's social control system, and a perceived positive ingroup emotional climate, which, in turn, should mediate the reinforcement of ingroup identification. Conversely, if the group is perceived to be unresponsive to deviance, ingroup emotions, perceived ingroup emotional climate, and trust in the group's institutions should become more negative, and social identification should be weakened.

To our knowledge, the previous idea has never been tested. However, it appears consistent with evidence that shows that positive ingroup emotions (e.g., security, trust, pride in being a group member, or the belief that the group will overcome current injustices and threats) are associated with individuals' ability to recover from negative collective emotional experiences, individuals' well-being, and perception that the ingroup contributes to general human welfare (De Rivera \& Paez, 2007; Fredrickson, 2009; Paez, Espinosa, \& Bobowik, 2013; Paez \& Rimé, 2014). In turn, negative emotions about the ingroup (e.g., despair, hopelessness, shame, insecurity, mistrust, moral outrage, or collective anger) seem to be associated with perceived group ineffectiveness, for instance in preventing social exclusion or loss of power (O’Mara, Jackson, Batson, \& Gaertner, 2011; Tangney, Stuewig, \& Mashek, 2007; cf. also Bar-Tal, Halperin, \& De Rivera, 2007; De Rivera \& Paez, 2007; Fischer \& Manstead, 2008). We may assume that ingroup identification is, to a large extent, a function of these factors.

\section{Overview and Hypotheses}

We test the previous idea in three studies. In Study 1, participants read a description of an embezzlement case. ${ }^{1}$ According to conditions, the offender was presented either as a Portuguese (ingroup condition) or as a Spanish (outgroup condition) citizen. Furthermore, half of the participants learned that the case had gone to trial (effective reaction condition), whereas the other half learned that the deadline for the trial had expired so that the case had not been brought to justice and the defendant had been "automatically acquitted" (ineffective reaction condition). Participants then responded to items assessing their perception that ingroup members do not value relevant standards and lack commitment to the group (anomie), their trust in the ingroup's social control system, and their level of ingroup identification. We expected participants to perceive more anomie, to trust less in the ingroup's social control system, and to identify less with the ingroup in the ineffective ingroup reaction condition than in all other conditions. In turn, in the effective ingroup reaction condition, participants should perceive less anomie, trust more in the ingroup's social control system, and identify more with the ingroup than in all other conditions. We also predicted that trust in the social control system and perceived anomie would mediate the association between induced group reaction and ingroup identification. That is, induced effectiveness of the ingroup's social control system should be associated with greater trust in that system and lower perceived anomie, which, in turn, should be associated with stronger ingroup identification. These mediations should occur only in the ingroup condition, in which the group's reaction 
has direct implications for the participants' social identity (Hutchinson et al., 2008; Marques, Paez, et al., 1998).

Study 2, though similar, differed from Study 1 in three ways. Firstly, participants learned that a survey conducted in the Portuguese (ingroup condition) or Spanish (outgroup condition) courts had allegedly shown that across that country there was a high frequency of reported crimes of corruption. Participants in the effective reaction condition read that these crimes had been brought to trial, whereas those in the ineffective reaction condition read that the crimes had not been judged due to expiring deadlines. Secondly, instead of asking about participants' trust in the social control system, we decided to more directly tap their perception of the ingroup's emotional climate: positive emotional climate or collective hope and optimism, and negative emotional climate or anomie. Thirdly, we used an alternative measure of anomie that we consider more suitable to the context of our study. We expected participants to be the most hopeful and optimistic about, to perceive the least anomie in, and to be the most identified with the ingroup, in the effective ingroup reaction condition, and to perceive the highest anomie, to be the least hopeful and optimistic, and to be the least identified in the ineffective ingroup reaction condition, as compared with the remaining conditions. We also expected hope and optimism, and perceived anomie to mediate between induced group reaction effectiveness and ingroup identification. In this experiment, we also propose that this should emerge only in the ingroup condition.

In Study 3, participants completed a questionnaire in which they indicated their perception of the efficacy of the Portuguese system in controlling corruption. Similar to Study 2, participants reported their perceptions of anomie, hope and optimism about the ingroup, as well as ingroup identification. In addition, we measured participants' trust in the group's social control system and ingroup emotions. We tested the mediation role of positive ingroup emotions in the association between group effectiveness and trust in the social control system, collective hope and optimism about the group, and lower perceived anomie. Indeed, the perception of successful ingroup social control should generate positive ingroup emotions and a perceived positive ingroup emotional climate. Conversely, the less effective individuals perceive the group to be, the less positive emotions about the group they should feel, and the more negatively they should perceive the group's emotional climate (higher anomie and lower hope and optimism). Trust, hope and optimism, and lower perceived anomie should predict stronger ingroup identification.

\section{Study 1}

\section{Method}

Participants and design. A convenience sample of 72 female and seven male Portuguese respondents, aged 18 to 48 years old ( $M=19.87$, $S D=4.25)$ participated in this study. Male participants varied between one and three by condition. There were no significant differences in sex, $\chi^{2}(3)=1.90, p=.593$, or age, $F(3,75)<1$, across experimental conditions.

We employed a 2 (offender's country: ingroup vs. outgroup) x 2 (reaction: effective vs. ineffective) full between-participants factorial design.

Procedure. We informed participants that they were taking part in a study about criminal profiles. They read an embezzlement case allegedly perpetrated either by a Portuguese (ingroup condition) or by a Spanish (outgroup condition) citizen. Participants in the effective reaction condition learned that the case had been instructed and brought to trial in the Portuguese (vs. Spanish) National Court. Participants in the ineffective reaction condition learned that the case had been instructed but it had not been brought to trial, because the legal deadlines had expired. To ensure that participants in both group reaction conditions would ignore the verdict, no information about the outcome of the process was provided.

Dependent measures. We measured participants' agreement $(1=I$ totally disagree; $7=I$ totally agree $)$ with statements tapping perceived anomie, trust in the 
social control system, and ingroup identification. Perceived anomie was an adaptation of the nine-item version of Srole's (1956, cited in Seeman, 1991) Anomia Scale (e.g., "Nowadays, a person has to live pretty much for today and let tomorrow take care of itself," "It's hardly fair to bring children into the world with the way things look for the future"). However, instead of using a 2-point scale, as suggested by the author, we used a 7-point scale for each item, consistent with the remaining response scales in the questionnaire (Cronbach's $\alpha=.65$ ). The statements employed to measure trust in the social control system, were: (a) "I think social control measures protect citizens and society against criminals"; (b) "I think social control reinforces our society's core values"; (c) "I think social control helps congregate collective forces to fight deviance"; and (d) "I think social control strengthens society." We averaged these items to a trust in the social control system score (Cronbach's $\alpha=.90)$. Finally, seven statements measured ingroup identification: (a) "I am committed to Portuguese society"; (b) "I am proud of being Portuguese"; (c) "I feel emotionally involved with Portuguese society"; (d) "I think I am similar to Portuguese citizens in general"; (e) "Being Portuguese is important for me"; (f) "I really like the Portuguese culture"; and (g) "I think there are plenty of nice things about Portugal." Answers were averaged to an ingroup identification score (Cronbach's $\alpha=.81$ ).

\section{Results}

Perceived anomie. We expected participants to perceive more and less anomie in the ineffective and effective ingroup reaction condition, respectively, than in the outgroup conditions. An Offender's Country $x$ Reaction ANOVA computed on the perceived anomie score, yielded a marginally significant effect of offender's country, $F(1,75)=$ $3.28, p=.074, \eta_{\mathrm{p}}^{2}=.042$, a significant effect of reaction $F(1,75)=5.38, p=.023, \eta_{\mathrm{p}}^{2}=.067$, and a nonsignificant interaction, $F(1,75)<1$. Participants perceived marginally more anomie in the offender's national group when the offender was an ingroup $(M=3.92, S D=0.90)$ than an outgroup member $(M=3.60, S D=0.79)$, and perceived more anomie when the crime had not been judged $(M=3.96, S D=0.82)$ than when it had been brought to justice $(M=3.54, S D=0.86)$.

Although the interaction was nonsignificant, the two main effects reveal different mean scores between experimental conditions. We thus have some support to inspect the means by using a planned comparison analysis (cf. Rosenthal, Rosnow, \& Rubin, 2000). On inspection, the means within conditions (see Table 1), show a pattern consistent with our prediction that perceived anomie should be higher in the ingroup ineffective reaction condition than in all other conditions. However, it did not confirm the complementary prediction that perceived anomie should be the lowest in the ingroup effective reaction condition. We therefore conducted a contrast analysis to test the former prediction. We assigned the contrast scores of +3 to the ingroup ineffective reaction condition, and -1 to the remaining conditions. Consistent with this prediction, the significant contrast showed that perceived anomie was higher in the ingroup ineffective reaction condition than in all other conditions, $t(75)=2.55, p=.013$ (see Table 1). Further inspection of the means indicates that within the ingroup condition participants in the ineffective condition tended to perceive more anomie in the group than did participants in the effective condition, $t(37)=1.77, p=.086$. In the outgroup condition, no differences in perceived anomie emerged as a function of reaction, $t(38)=$ $1.50, p=.142$.

Trust in the social control system. We expected participants to report higher and lower trust in the social control system in the ingroup effective and ineffective reaction condition, respectively, than in all other conditions. An Offender's Country $x$ Reaction ANOVA computed on the trust in the social control system score yielded a significant effect of offender's country, $F(1,75)=8.49$, $p=.005, \eta_{\mathrm{p}}{ }^{2}=.102$, a marginally significant effect of reaction $F(1,75)=3.08, p=.083, \eta_{p}^{2}=.039$, and a significant Offender's Country x Reaction interaction $F(1,75)=4.24, p=.043, \eta_{\mathrm{p}}{ }^{2}=.053$. The offender's country effect shows that participants trusted in the social control system more in 
Table 1. Means and standard deviations of anomie, trust in the social control system (trust), and ingroup identification as a function of offender's country and reaction (Study1).

\begin{tabular}{|c|c|c|c|c|c|c|c|c|}
\hline \multirow[t]{4}{*}{ Reaction } & \multicolumn{8}{|c|}{ Offender's country } \\
\hline & \multicolumn{4}{|c|}{ Ingroup } & \multicolumn{4}{|c|}{ Outgroup } \\
\hline & \multicolumn{2}{|c|}{ Effective } & \multicolumn{2}{|c|}{ Ineffective } & \multicolumn{2}{|c|}{ Effective } & \multicolumn{2}{|c|}{ Ineffective } \\
\hline & $M$ & $S D$ & $M$ & $S D$ & $M$ & $S D$ & $M$ & $S D$ \\
\hline Anomie & 3.68 & 0.94 & 4.18 & 0.81 & 3.40 & 0.75 & 3.77 & 0.80 \\
\hline Trust & 5.49 & 0.79 & 4.45 & 1.29 & 4.13 & 1.44 & 4.21 & 1.24 \\
\hline Ingroup identification & 6.21 & 0.88 & 4.86 & 1.33 & 5.84 & 1.15 & 5.56 & 1.14 \\
\hline
\end{tabular}

the ingroup $(M=4.98, S D=1.17)$ than in the outgroup condition $(M=4.18, S D=1.32)$. Moreover, participants tended to show more trust in the social control system in the effective condition $(M=4.83, S D=1.33)$ than in the ineffective condition $(M=4.33, S D=1.25)$.

To directly examine our predictions, we conducted two contrast analyses on the trust in the social control system score. In one analysis, we assigned the value +3 to the ingroup effective reaction condition and the value -1 to the remaining conditions. In the other analysis, we assigned -3 to the ingroup ineffective reaction condition and +1 to the remaining conditions. The analyses partially supported our predictions. Indeed, the first contrast was significant, but the second was not, $t(75)=3.90, p<.001$ and $t(75)<$ 1 , respectively; see Table 1 . Further inspection on the means indicate that, similarly to what we observed with the perceived anomie score, within the ingroup condition, participants trusted the group's social control system more in the effective than in the ineffective condition, $t(37)=3.06$, $p=.004$. No such difference emerged in the outgroup condition, $t(38)<1$.

Ingroup identification. An Offender's Country x Reaction ANOVA conducted on the ingroup identification score yielded significant effects of reaction, $F(1,75)=10.07, p=.002, \eta_{\mathrm{p}}^{2}=.120$, indicating that participants showed stronger identification in the effective condition $(M=6.03$, $S D=1.01)$ than in the ineffective condition
$(M=5.23 ; S D=1.27)$. The effect of offender's country was not significant, $F(1,75)<1$. More relevant to our hypothesis, we obtained a significant Offender's Country x Reaction interaction, $F(1,75)=4.26, p=.043, \eta_{\mathrm{p}}^{2}=.054$.

We expected participants to report higher and lower levels of national identification in the ingroup effective reaction, and in the ingroup ineffective reaction conditions respectively, than in both outgroup conditions. In order to test our prediction that national identification would be higher in the ingroup effective reaction condition than in all other conditions, we assigned +3 to the ingroup effective reaction condition and -1 to all other conditions. In order to test the prediction that national identification would be weaker in the ingroup ineffective reaction than in all other conditions, we assigned -3 to the ingroup ineffective reaction condition and +1 to all other conditions. Both contrasts supported our prediction, $t(75)=2.71, p=.008$ and $t(75)=3.39$, $p=.001$, respectively. Participants reported the highest and lowest national identification in the ingroup effective reaction condition and in the ingroup ineffective reaction condition respectively (see Table 1). Again, consistent with the previous dependent measures, further inspection of the means indicated that, within the ingroup condition, participants showed stronger identification with the ingroup in the effective than in the ineffective condition, $t(37)=3.79, p=.001$, whereas, in the outgroup condition, reaction did not significantly affect identification $t(38)<1$. 
Table 2. Pearson moment-product correlations between reaction, anomie, trust in the social control system (trust) and ingroup identification (identification) by offender's country (Study 1).

\begin{tabular}{|c|c|c|c|c|c|c|}
\hline & \multicolumn{3}{|l|}{ Ingroup } & \multicolumn{3}{|c|}{ Outgroup } \\
\hline & 1. & 2. & 3. & 1. & 2. & 3. \\
\hline \multicolumn{7}{|l|}{ 1. Reaction } \\
\hline 2. Anomie & $-.279 \dagger$ & & & -.236 & & \\
\hline 3. Trust & $.449 * *$ & -.127 & & -.032 & -.210 & \\
\hline 4. Identification & $.528^{* * *}$ & -.078 & $.368^{*}$ & .127 & -.031 & -.149 \\
\hline
\end{tabular}

Note. ${ }^{*} p \leqslant .05 ; * * p \leqslant .01 ; * * * p \leqslant .001 ; \not p \leqslant .10$.

Mediation. We expected trust in the social control system and anomie to mediate the association between reaction and ingroup identification, but only in the ingroup condition. Product-moment Pearson correlations between these measures were significant only when trust in the social control system was involved (when anomie was involved all $r \mathrm{~s} \leqslant .279$, all $p \mathrm{~s} \geqslant .086$ ). As can be seen in Table 2, only in the ingroup condition was reaction significantly associated with trust in the social control system $(r=.449, p=.004)$ and with ingroup identification $(r=.528, p=.001)$. Trust in the social control system was also significantly and positively associated with ingroup identification $(r=.368, p=.021)$. In the outgroup condition, all correlations were nonsignificant (all $r s \leqslant .236$, all $p s \geqslant .142$ ) providing no support for further inspection of the mediation process in this condition. We thus conducted a mediation analysis using the PROCESS macro with 10,000 bootstraps (Model 4; see Hayes, 2013) only within the ingroup condition, taking reaction as the predictor variable, ingroup identification as the dependent variable, and trust in the social control system and perceived anomie as the mediator variables. The joint effect of reaction, trust in the social control system, and anomie significantly explained ingroup identification, $F(3,35)=5.14, p=.005$. This model accounted for $31 \%$ of the variance. Nevertheless, the predicted mediation was not supported, indirect effect: $b=0.14, S E=0.23 ; 95 \% \mathrm{CI}=$ $[-0.25,0.69]$; total effect: $b=1.35, S E=0.36, t$ $=3.79, p=.001 ; 95 \% \mathrm{CI}=[0.63,2.07]$; direct effect: $b=1.22, S E=0.42, t=2.92, p=.006$;
$95 \% \mathrm{CI}=[0.31,2.06]$. Indeed, in the mediation model, neither the indirect effect regarding anomie, $b=-0.05, S E=0.11 ; 95 \% \mathrm{CI}=[-0.38$, $0.10]$ nor that regarding trust in the social control system, $b=0.19, \mathrm{SE}=0.21 ; 95 \% \mathrm{CI}=[-0.11$, 0.75] significantly predicted identification. Together, these results suggest that reaction directly predicts identification, as well as trust in the social control system and anomie. Nevertheless, trust in the social control system $(b=0.18$, $S E=0.17 ; t=1.04, p=.304)$ and anomie $(b=$ $0.11, S E=0.21 ; t<1)$ do not directly predict identification.

\section{Discussion}

On balance, results supported our hypotheses fairly well. We found that perceived anomie, increased more as a function of ingroup than outgroup deviance. In addition, the group's ability to effectively react to this deviance affected perceived anomie, trust in the group's social control, and social identification, in the case of the ingroup, but not of the outgroup. The predicted interaction between group effectiveness and offender's group was marginally significant in the anomie score. Thus, the results supported our prediction that perceived anomie should be higher in the ineffective ingroup condition than in all other conditions and that participants who learned that the ingroup was effective in dealing with deviance should trust more in the social control system than should participants in the other conditions. Another prediction that was fully supported concerns the effect of group 
effectiveness on social identification. Participants who had been informed that the ingroup was ineffective identified less, whereas those who had been informed that the ingroup was effective identified more with the ingroup, as compared to the outgroup conditions. This suggests that perceived ingroup effectiveness can, indeed, be a powerful determinant of ingroup identification.

Although these preliminary results look promising, we did not find support for our predictions that perceived anomie should be lower in the ingroup effective reaction condition, or that trust in the social control system should be lower in the ingroup ineffective reaction condition, as compared to all other conditions. One possible, though speculative, explanation for these results may be the fact that the items employed were too general to account for participants' opinions regarding the specific context of the study. Another possibility is that the fact that there was a single case of deviance induced participants to view this case as only mildly representative of the group's typical reactions to deviance.

The results did not support the predicted mediation model either. Indeed, neither perceived anomie nor trust in the social control system emerged as factors likely to reinforce the association between induced group reaction and ingroup identification. This may have been due to a combination of three reasons. First, the small size of our sample may have increased the likelihood of Type II error, thus making it difficult for significant correlational results to emerge. Second, the reaction manipulation may have failed to induce a perception of group effectiveness in controlling deviance in general. Indeed, participants may have dismissed this single case by making dispositional attributions to the deviant target-person, or by constructing lack of group response as a lowprobability event of little relevance to a general appraisal of the group. Third, and most likely, we may have missed an important step in the mediation process between trust in the social control system or perceived anomie and ingroup identification. Indeed, based on findings by De Rivera and Paez (2007), Fredrickson (2009), and Swann and colleagues (Swann, Gómez, Seyle, Morales, \& Huici, 2009), it is possible that a positive emotional climate is an important missing link between trust in the social control system and perceived anomie, on the one hand, and social identification, on the other hand. In this vein, we may expect trust in the social control system and perceived anomie to be positively and negatively associated, respectively, with positive emotional climate in the ingroup, which, in turn, should be associated with stronger identification. In Study 2, we tested this additional mediation step, by including emotional climate measures (collective hope and optimism), and by using a more contextdependent measure of perceived anomie. In addition, we increased our sample size, and changed the reaction manipulation.

\section{Study 2}

In Study 2 we measured perceived anomie, ingroup identification, and collective hope and optimism about the ingroup as a means of adding a further dimension of emotional climate (besides the perceived negative anomic climate) in association with the (in)effectiveness of the group's reaction. We expected higher hope and optimism about the ingroup, lower perceived anomie, and higher ingroup identification to be affected by the induced perception that the ingroup is able to control deviance. Complementarily, we expected participants to report higher perceived anomie in the ingroup, lower hope and optimism, and weaker ingroup identification facing an ineffective ingroup reaction. Finally, as mentioned before, we expected anomie and hope and optimism to mediate group reaction and ingroup identification, through a serial multiple mediator model. Specifically, we expected (a) (in)effectiveness of the group's reaction to predict perceived anomie (as we found in Study 1), (b) perceived anomie to predict collective hope and optimism, and (c) collective hope and optimism to predict ingroup identification.

\section{Method}

Participants and design. Participants were 100 female and 73 male Portuguese respondents, aged 15 to 42 years old $(M=21.37, S D=4.41)$. 
There were no significant differences in $\operatorname{sex} \chi^{2}(3)$ $=1.51, p=.681$, or age $F(3,169)=1.50, p=.217$, across experimental conditions. In the inspection of residuals, the answers of three participants were not considered due to outlier scores $( \pm 3$ $S D)$ in the identification measure $(n=1$; score $=$ 4.20) and in the hope and optimism $(n=2$; both scores $=2.25)$ scores.

We employed a 2 (offender's country: Portugal vs. Spain) x 2 (reaction: effective vs. ineffective) full between-participants factorial design.

Procedure. To manipulate reaction, we informed participants that a previous survey conducted in courts in both Portugal or Spain (respectively in the ingroup or outgroup conditions) had shown that, "from the 856 crimes of corruption that had been reported in 2008," either the majority had been brought to justice (effective reaction condition) or that most had not been brought to justice as the legal deadlines had expired (ineffective reaction condition). ${ }^{2}$

Dependent measures. After reading the information, participants responded to items about perceived ingroup's emotional climate and ingroup identification.

Emotional climate. Participants responded to the following items $(1=I$ totally disagree; $7=I$ totally agree): "Considering the way things happen in Portugal, it is true that crime does pay"; "People cannot get what they deserve by legal means"; "In Portugal anything goes"; "It is worthwhile fighting for social justice in Portugal"; "I believe that the Portuguese will overcome their difficulties"; "In Portugal, people can feel safe"; "The Portuguese people are committed to creating a better country."3 A principal components analysis with varimax rotation computed on these items extracted two factors accounting for $55.60 \%$ of the total variance $(32.61 \%$ and $22.99 \%$ respectively; see Table 3). We named the first factor Hope and Optimism (Cronbach's $\alpha=.75$ ) corresponding to a positive emotional climate, and the second factor Anomie (Cronbach's $\alpha=.53$ ), corresponding to a negative emotional climate.
Ingroup identification. This measure is identical to the one employed in the previous study. We averaged the identification items to an ingroup identification score (Cronbach's $\alpha=.84$ ).

\section{Results}

Emotional climate. We predicted that perception of the ingroup should, respectively, be more positive (hopeful and optimistic) and less negative (anomic), and more negative (anomic) and less positive (hopeful and optimistic) in the ingroup effective reaction and in the ingroup ineffective reaction conditions (respectively), than in all other conditions.

An Offender's Country x Reaction ANOVA computed on the hope and optimism score yielded significant effects of offender's country, $F(1,169)=3.92, p=.049, \eta_{\mathrm{p}} 2=.023$, reaction, $F(1,169)=6.42, p=.012, \eta_{p} 2=.037$ and Offender's Country x Reaction $F(1,169)=4.04$, $p=.046, \eta_{\mathrm{p}} 2=.023$. Participants showed higher hope and optimism in the ingroup $(M=4.21, S D$ $=1.14)$ than in the outgroup $(M=3.88, S D=$ 1.20) condition. Moreover, participants showed higher hope and optimism in the effective $(M=$ $4.25, S D=1.08)$ than in the ineffective condition $(M=3.83, S D=1.24)$. To examine this result further, we conducted two contrast analyses to test the idea that hope and optimism should be higher in the ingroup effective reaction condition as compared to the remaining conditions. We thus ascribed +3 to the ingroup effective reaction condition and -1 to the remaining conditions. We also tested the idea that hope and optimism should be lower in the ingroup ineffective reaction condition. Therefore, we ascribed -3 to the ingroup ineffective reaction condition and +1 to the other conditions. Only the first contrast proved to be significant, $t(169)=3.64$, $p<.001$, and $t(169)=1.48, p=.141$. Nevertheless, inspection of the means indicates that within the ingroup condition participants showed higher hope and optimism in the effective than in the ineffective condition, $t(77.78)=3.38, p=.001$. In the outgroup condition, participants did not significantly differentiate hope and optimism by 
Table 3. Emotional climate: Item factor scores after varimax rotation (Study 2).

\begin{tabular}{lcc}
\hline Emotional climate & Factor 1 Hope and Optimism & Factor 2 Anomie \\
\hline In Portugal, people can feel safe & .821 & -.025 \\
I believe that the Portuguese will overcome their & .810 & -.205 \\
difficulties & .719 & -.010 \\
The Portuguese people are committed to creating a & & -.288 \\
better country & .608 & .750 \\
It is worthwhile fighting for social justice in Portugal & .016 & .703 \\
People cannot get what they deserve by legal means & -.224 & .654 \\
Considering the way things happen in Portugal, it is & & \\
true that crime does pay & -.118 & \\
In Portugal anything goes &
\end{tabular}

Table 4. Means and standard deviations of anomie, hope and optimism, and ingroup identification by offender's country and reaction (Study 2).

\begin{tabular}{|c|c|c|c|c|c|c|c|c|}
\hline \multirow[t]{4}{*}{ Reaction } & \multicolumn{8}{|c|}{ Offender's country } \\
\hline & \multicolumn{4}{|c|}{ Ingroup } & \multicolumn{4}{|c|}{ Outgroup } \\
\hline & \multicolumn{2}{|c|}{ Effective } & \multicolumn{2}{|c|}{ Ineffective } & \multicolumn{2}{|c|}{ Effective } & \multicolumn{2}{|c|}{ Ineffective } \\
\hline & $M$ & $S D$ & $M$ & $S D$ & $M$ & $S D$ & $M$ & $S D$ \\
\hline Anomie & 4.00 & 1.20 & 4.60 & 0.97 & 4.16 & 1.50 & 4.04 & 1.33 \\
\hline Hope and optimism & 4.62 & 0.91 & 3.83 & 1.20 & 3.93 & 1.11 & 3.84 & 1.28 \\
\hline Ingroup identification & 6.21 & 0.88 & 4.86 & 1.33 & 5.84 & 1.15 & 5.56 & 1.14 \\
\hline
\end{tabular}

reaction $(t<1)$. This result is consistent with our findings in Study 1.

The Offender's Country x Reaction effect ANOVA computed on the anomie score yielded no significant main effects (both $F_{\mathrm{S}} \leqslant 1.52, p \geqslant$ .220), and a marginally significant Offender's Country $\mathrm{x}$ Reaction effect, $F(1,169)=3.42$, $p=.066, \eta_{\mathrm{p}} 2=.020$ (see Table 4 ). To examine this interaction, we conducted two contrast analyses, testing the prediction that perceived anomie should be higher in the ingroup ineffective reaction condition as compared to all other conditions. We thus ascribed +3 to the ingroup ineffective reaction condition and -1 to remaining conditions. We also tested the prediction that participants should perceive lower anomie in the ingroup effective reaction condition as compared to the remaining conditions. Thus, we ascribed the value -3 to the ingroup effective reaction condition and +1 to the other conditions. Again, the former contrast was significant, but the latter was not, $t(169)=2.36, p=.020$, and $t(169)=$ $1.16, p=.249$, respectively. In line with our predictions and, again, consistent with the findings of Study 1, participants perceive more anomie in the ingroup ineffective than in the ingroup effective condition, $t(80)=2.48, p=.015$. In the outgroup condition, reaction did not affect perceived anomie $(t<1)$.

Ingroup identification. We expected participants to identify with the ingroup the most and the least in the ingroup effective reaction and ingroup ineffective reaction conditions, respectively. To test this prediction, we conducted an Offender's Country $x$ Reaction ANOVA on the ingroup identification score. We found a marginally significant effect of offender's country, $F(1,169)=2.94$, $p=.088, \eta_{\mathrm{p}} 2=.017$, and significant effects of reaction, $F(1,169)=19.25, p<.001, \eta_{\mathrm{p}} 2=.102$, 
and of Offender's Country x Reaction interaction, $F(1,169)=14.86, p<.001, \eta_{\mathrm{p}} 2=.081$. Participants identified more with the ingroup in the ingroup $(M=5.50, S D=1.14)$ than in the outgroup $(M=5.26, S D=1.02)$ condition. Moreover, identification was higher in the effective $(M=$ $5.70, S D=0.94)$ than in the ineffective $(M=5.07$, $S D=1.12)$ condition. As we did in Study 1, we conducted two contrast analyses on the ingroup identification score. In order to test the idea that national identification would be stronger in the ingroup effective reaction condition than in all other conditions, we assigned +3 to the ingroup effective reaction condition and -1 to all other conditions. In order to test the idea that national identification would be weaker in the ingroup ineffective reaction than in all other conditions, we assigned -3 to the ingroup ineffective reaction condition and +1 to all other conditions. In support of our prediction, both contrasts were significant, $t(169)=5.56, p<.001$ and $t(169)=3.77$, $p<.001$, respectively (see Table 4). Again consistent with our results in Study 1, inspection of the means indicates that, within the ingroup condition, participants identified more with the ingroup in the effective than in the ineffective condition, $t(64.16)=6.04, p<.001$. In the outgroup condition, participants did not significantly differentiate identification with the ingroup by reaction $(t<1)$.

Mediation. We expected anomie and, subsequently, hope and optimism to mediate the association between reaction and ingroup identification only in the ingroup condition. As we expected, product-moment Pearson correlations between these measures showed significant associations only in the ingroup condition (all $r s$ $\geqslant .267$, all $p \mathrm{~s} \leqslant .015$; see Table 5 ). In the outgroup condition, the only significant correlation was between hope and optimism and ingroup identification $(r=.597, p<.001$; for the remaining associations: $r \leqslant .186, p \geqslant .077)$. Based on these results we conducted two serial multiple mediator model analyses using the PROCESS macro with 10,000 bootstraps (Model 6; see Hayes, 2013). One such analysis was conducted within the ingroup condition. The other analysis was conducted within the outgroup condition. In both models we took anomie as the first mediator and hope and optimism as the second mediator variables. Reaction was the predictor and ingroup identification was the dependent variable. Within the ingroup condition, the joint effect of reaction, anomie, and hope and optimism, significantly predicted ingroup identification, $F(3,78)=$ $16.97, p<.001$. The model accounted for $39 \%$ of the variance. The predicted mediation was significant; indirect effect of the serial model: $b=0.08$, $S E=0.05,95 \% \mathrm{CI}=[0.01,0.25]$; total indirect effect: $b=0.26, S E=0.11 ; 95 \% \mathrm{CI}=[-0.08$, $0.51]$; direct effect: $b=0.99, S E=0.22, t=4.59$, $p<.001 ; 95 \% \mathrm{CI}=[0.56,1.42]$. Indeed, in the regression model, reaction predicts anomie, which, in turn, predicts hope and optimism. Hope and optimism seems to be a determinant variable to explain ingroup identification. Within the outgroup condition, the joint effect of reaction, anomie, and hope and optimism significantly predicted ingroup identification, $F(3,87)=$ 16.23, $p<.001$. This model accounted for $36 \%$ of the variance. Nevertheless, the predicted mediation was not significant; indirect effect of the serial model: $b=-0.01, S E=0.03,95 \% \mathrm{CI}=$ $[-0.09,0.05]$; total indirect effect: $b=0.046, \mathrm{SE}$ $=0.13 ; 95 \% \mathrm{CI}=[-0.22,0.31]$; direct effect: $b=$ $0.04, S E=0.17, t<1$. In brief, these results indicate that effective ingroup reaction is associated to a higher level of ingroup identification, lower perceived ingroup anomie, and consequent higher hope and optimism regarding the ingroup.

\section{Discussion}

These results are consistent with our predictions and with the results of Study 1. They suggest that belief in the ingroup's ability to control deviance is a powerful determinant of people's perceptions of the group's emotional climate and of their identification with that group, whereas ingroup inefficacy induces a perceived negative emotional climate in the form of perceived anomie. Indeed, participants who were informed that the ingroup effectively implemented social control, reported higher hope and 
Table 5. Pearson moment-product correlations between reaction, anomie, hope and optimism, and ingroup identification (identification) by offender's country (Study 2).

Offender's country

\begin{tabular}{|c|c|c|c|c|c|}
\hline \multicolumn{3}{|l|}{ Ingroup } & \multicolumn{3}{|c|}{ Outgroup } \\
\hline 1. & 2. & 3. & 1. & 2. & 3. \\
\hline$-.267 *$ & & & .043 & & \\
\hline $.350 * *$ & $-.468 * * *$ & & .038 & -.145 & \\
\hline $.549^{* * *}$ & $-.269 *$ & $.479 * * *$ & .040 & -.186 & $.597 * * *$ \\
\hline
\end{tabular}

1. Reaction

2. Anomie

3. Hope and optimism

$.350^{* *}$

.038

4. Identification

Note. ${ }^{*} p \leqslant .05 ; * * p \leqslant .01 ; * * * \leqslant .001 ; \dagger p \leqslant .10$.

optimism and stronger ingroup identification than did participants who received similar information about the outgroup. Conversely, participants who received information that the ingroup was ineffective perceived higher anomie in, and reported weaker identification with, the ingroup than did participants who learned about the outgroup's ineffectiveness. It is worthwhile noting that contrary to what could be expected, but consistent with the results of Study 1, perceived ingroup effectiveness did not appear to decrease perceptions of ingroup anomie, whereas perceived ingroup inefficacy did not affect perceived ingroup hope and optimism. Finally, hope and optimism mediated between perceived anomie and ingroup identification.

In spite of the fact that results of Study 2 generally support our predictions, three questions remain to be addressed. Firstly, it might be argued that participants in the effective reaction condition were implicitly led to believe that the deviants had actually been punished, whereas in the ineffective reaction condition, it was clear that the deviants had not been punished. Consequently, the results may have been due to the fact that participants felt satisfied or unsatisfied with respect to the retributive motive that, supposedly, often underlies punishment (e.g., Carlsmith, 2006; Carlsmith, Darley, \& Robinson, 2002). Secondly, our results do not yet provide direct evidence about the process through which perceived ingroup effectiveness sustains or undermines people's trust in, and commitment to, the ingroup and its values. Thirdly, results of Studies 1 and 2 do not directly inform on whether it is (positive or negative) ingroup beliefs that stem from ingroup identification, as is implicit in most social identification analyses, or, if as we propose, it is the strength of social identification that stems from beliefs about the ingroup. Our third study aimed to address these questions directly.

\section{Study 3}

In our third study, instead of inducing group (in) effectiveness as we did in the previous studies, we adopted a correlational strategy. We also included measures tapping all the concepts employed in the previous studies (ingroup identification, trust in the social control system, and positive and negative emotional climate). Finally, participants responded to measures designed to check for perceived ingroup effectiveness and ingroup emotions. We included ingroup emotions based on the assumption that emotions generated by the group's perceived effectiveness to deal with deviance can be an important mediator of ingroup identification (cf. De Rivera \& Paez, 2007; Fredrickson, 2009; Swann et al., 2009). Based on the idea that positive ingroup emotions (e.g., security, trust, pride in being a group member, belief that the group will overcome current injustices and threats) are associated with individuals' ability to recover from negative collective emotional experiences, individuals' well-being, and perception that the ingroup contributes to general human welfare (De Rivera \& 
Paez, 2007; Fredrickson, 2009; Paez et al., 2013; Paez \& Rimé, 2014), and on the evidence collected in the previous studies, we reasoned that perceived effectiveness should generate positive ingroup emotions which, in turn, should predict increased trust in the social control system and decreased perception of anomie, and trigger collective hope and optimism about the ingroup. This should reinforce ingroup identification. Accordingly, this model summarizes the results of the preceding studies.

\section{Method}

Participants. Participants were 115 Portuguese nationals $\left(n_{\text {female }}=75 ; n_{\text {male }}=40\right)$, aged from 17 to 45 years old $(M=20.64, S D=3.26)$.

Procedure. One researcher approached participants in several institutions - universities, employment agencies, and small companies_-and invited them to respond to a self-administered questionnaire dealing with “people's opinions about how several EU countries, including Portugal, deal with corruption."

\section{Measures}

Perceived effectiveness. A first set of items tackled participants' perception of Portugal's effectiveness in detecting, prosecuting, and punishing corruption: "The Portuguese society can effectively track down corruption cases when they occur"; "The Portuguese society can effectively spot the people involved in corruption crimes"; "Corruption is prosecuted effectively by the Portuguese system"; "Corruption cases are prosecuted effectively by the Portuguese courts"; "The Portuguese system sanctions corruption effectively" $(1=I$ disagree; $7=I$ agree $)$. Thus, we created a perceived effectiveness score by averaging the responses to these items (Cronbach's $\alpha=.94 ; M$ $=3.02, S D=1.53$ ).

Ingroup emotions. The second set of measures tapped ingroup emotions (positive, negative antagonist, and negative resignation) associated with participants' perceived group effectiveness. Participants stated the extent to which they felt each of 12 emotions, "When I think about how corruption is dealt with in Portugal, I feel: outraged, shocked, embarrassed, ashamed, resigned, indifferent, distant, unconcerned, confident, secure, hopeful, and cheerful" (1 = I totally disagree 7 = I totally agree) .

A principal components analysis computed on these items extracted three factors accounting for $26.80 \%, 25.55 \%$, and $23.98 \%$ of the $76.34 \%$, respectively, of the total variance. We named the three factors, respectively, Negative Antagonistic Emotions (including negative moral emotions and moral outrage), Positive Emotions (including security and hope), and Negative Resignation Emotions (including resignation and indifference; see Table 6). We thus computed a negative antagonistic emotions, a positive emotions, and a negative resignation emotions indexes, as the mean score of items that presented the highest factor loadings (Cronbach's $\alpha=.90, .90$, and .85 , respectively; negative antagonistic emotions: $M=$ 4.43, $S D=1.57$; positive emotions: $M=3.39, S D$ = 1.46; negative resignation emotions: $M=2.53$, $S D=1.31)$.

Trust in the social control system. In the third set of measures, participants indicated how much they agreed or disagreed that the ingroup social control mechanisms are trustworthy: "We should trust our political leaders more"; "Our laws against corruption are effective"; "Our justice system is effective" ( $1=I$ totally disagree; $7=I$ totally agree). We averaged these items to a trust in the social control system score (Cronbach's $\alpha=$ $.90 ; M=3.05, S D=1.53)$.

Emotional climate and ingroupidentification. Finally, emotional climate (hope and optimism, and anomie) and ingroup identification measures were identical to those employed in Study 2 (Cronbach's $\alpha=.83, .78$, and .93 , respectively; hope and optimism: $M=4.43, S D=1.33$; anomie: $M=4.08, S D=1.76$; ingroup identification: $M=4.72, S D=1.45)$. 
Table 6. Ingroup emotions: Item factor scores after varimax rotation (Study 3).

\begin{tabular}{lclc}
\hline Emotions & Factor 1 Negative Antagonist & Factor 2 Positive & Factor 3 Negative Resignation \\
\hline Shocked & .913 & -.046 & -.091 \\
Outraged & .903 & -.108 & -.128 \\
Ashamed & .818 & -.188 & .170 \\
Embarrassed & .789 & -.178 & .084 \\
Cheerful & -.156 & .882 & .040 \\
Hopeful & -.050 & .877 & -.172 \\
Secure & -.217 & .850 & .042 \\
Confident & -.075 & .839 & .067 \\
Distant & -.138 & -.073 & .895 \\
Unconcerned & -.187 & -.026 & .879 \\
Indifferent & .102 & .065 & .835 \\
Resigned & .362 & .021 & .715 \\
\hline
\end{tabular}

\section{Results}

Product-moment correlations. We expected perceived effectiveness to predict participants' identification with the Portuguese national group. More specifically, we expected that the more participants consider that the ingroup is able to control deviance, the stronger their identification with the Portuguese society would be. We also expected this association to be mediated by positive ingroup emotions, stronger trust in the social control system, lower perceived anomie, and, stronger hope and optimism about the ingroup. We also expected this process to be more effective in explaining variance in our data than if we considered ingroup identification as the predictor of group effectiveness, positive ingroup emotions, trust in the social control system, and emotional climate. In order to test this hypothesis, we first correlated all the measures (see Table 7).

As expected, perceived effectiveness was significantly associated with positive emotions, emotional climate (hope and optimism, and anomie), trust in the social control system, and ingroup identification. The more effective participants perceived the group to be, the more they reported positive emotions $(r=.563, p<.001)$, the less they perceived the group to be anomic $(r=-.316$, $p=.001)$, the more they expressed trust in the social control system $(r=.722, p<.001)$, the more hopeful and optimistic they were about it $(r=.514, p<.001)$, and the more they identified with it $(r=.404, p<.001)$.

Moreover, perceived anomie is significantly and negatively correlated with positive emotions $(r=-.301, p=.001)$ and with trust in the social control system $(r=-.245, p=.008)$. Perceived anomie correlated positively with negative resignation emotions $(r=.212, p=.023)$. The more participants perceived the group to be anomic, the less they trusted its national social control system, the more resignation they expressed, and the less positive ingroup emotions they manifested. Anomie tended to be negatively correlated with ingroup identification $(r=-.155, p=.098)$ with hope and optimism about the ingroup $(r=-.316, p<.001)$, and with perceived effectiveness $(r=-.316, p<.001)$. Hope and optimism about the ingroup was positively associated with trust in the social control system $(r=.594, p<.001)$, with positive emotions $(r=.388, p<.001)$ and with ingroup identification $(r=.722, p<.001)$.

Finally, positive emotions were also associated with ingroup identification $(r=.256$, $p=.006)$. The more participants expressed positive ingroup emotions, the more they identified with the group. This was not the case for correlations involving negative antagonistic emotions and negative resignation emotions. Negative antagonistic emotions were negatively and significantly associated with perceived effectiveness 
Table 7. Bivariate correlations matrix and descriptive statistics (Study 3).
$M \quad S D 1$.
2.
3.
4.
5.
6.
7.

1. Perceived Effectiveness $3.02 \quad 1.53$

2. Positive Ingroup motions $3.39 \quad 1.46 \quad .563^{* * *}$

3. Negative Antagonistic $4.43 \quad 1.57 \quad-.245^{* *} \quad-.293^{* *}$ Emotions

4. Negative Resignation Emotions

5. Trust in the Social Control System

6. Anomie

7. Hope and Optimism

$\begin{array}{llll}2.53 & 1.31 & -.148 & -.018\end{array}$ .045

8. Ingroup identification

$\begin{array}{lllll}3.05 & 1.53 & .722^{* * *} \quad .625^{* * *}-.248^{* *}-.136\end{array}$

$\begin{array}{lllllll}4.08 & 1.76 & -.316^{* * *} & -.301^{* *} & .169 \dagger & .212^{*} & -.245^{* *}\end{array}$

$\begin{array}{llllllll}4.43 & 1.33 & .514^{* * *} & .388^{* * *} & -.041 & -.329 * * * & .594 * * * & -.316^{* * *}\end{array}$

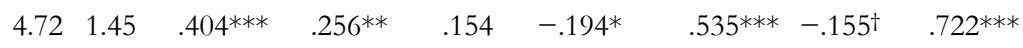

Note. ${ }^{*} p \leqslant .05 ; * * p \leqslant .01 ; * * * p \leqslant .001 ; \not p \leqslant .10$.

$(r=-.245, p=.008)$ and with trust in the social control system $(r=-.248, p=.008)$ but not with the other measures (all $r s<.169, p>.077$ ). Negative resignation emotions correlated significantly with hope and optimism $(r=-.329$, $p<.001)$ and with ingroup identification $(r=-.194, p=.044)$, but not with perceived effectiveness. These results suggest that positive emotions are the most important component of the mediation of all three types of ingroup emotions, between perceived effectiveness and ingroup identification.

It is worthy of note that the previous results support the two predicted serial multiple mediator models. One of these models takes perceived effectiveness as the predictor, ingroup identification as the dependent measure, trust in the social control system as the first mediator variable, and hope and optimism as the second mediator. The other model takes perceived effectiveness as the predictor, ingroup identification as the dependent measure, anomie as the first mediator variable, and hope and optimism as the second mediator. All associations between these variables are, indeed, significant.

Mediation analyses involving perceived effectiveness, trust in the group's social control system, anomie, hope and optimism, and ingroup identification. Based on our hypotheses and on the bivariate product-moment correlations reported before, we tested the two predicted serial multiple mediator models with PROCESS macro with 10,000 bootstraps (PROCESS, Model 6; see Hayes, 2003; Figure 1).

Both predicted serial multiple mediator models were significant. Indeed, Model 1 stated that perceived effectiveness would predict ingroup identification via trust in the social control system and hope and optimism. This model was fully supported. The joint effect of perceived effectiveness, trust in the social control system, and hope and optimism on ingroup identification was significant; $F(3,111)=42.44, p<.001$. The model accounted for $53 \%$ of the variance; indirect effect regarding the serial multiple mediator model: $b=0.28, S E=0.08,95 \% \mathrm{CI}=[0.16$, 0.47]; total effect: $b=0.38, S E=0.08, t=4.69$, $p<.001 ; 95 \% \mathrm{CI}=[0.22,0.54]$; total indirect effect: $b=0.42, S E=0.09 ; 95 \% \mathrm{CI}=[0.27,0.62]$; direct effect: $b=-0.04, S E=0.09, t<1$. Model 2 was identical to the one tested in Study 2. According to this model, perceived effectiveness should predict ingroup identification via anomie, and hope and optimism. This model was also supported. The joint effect of perceived effectiveness, anomie, and hope and optimism on ingroup identification was significant; $F(3,111)=43.25$, $p<.001$. The model accounted for $54 \%$ of the variance; indirect effect regarding the serial multiple mediator model: $b=0.04, S E=0.02,95 \% \mathrm{CI}$ $=[0.01,0.10]$; total effect: $b=0.38, S E=0.08, t=$ $4.69, p<.001 ; 95 \% \mathrm{CI}=[0.22,0.54] ;$ total indirect 


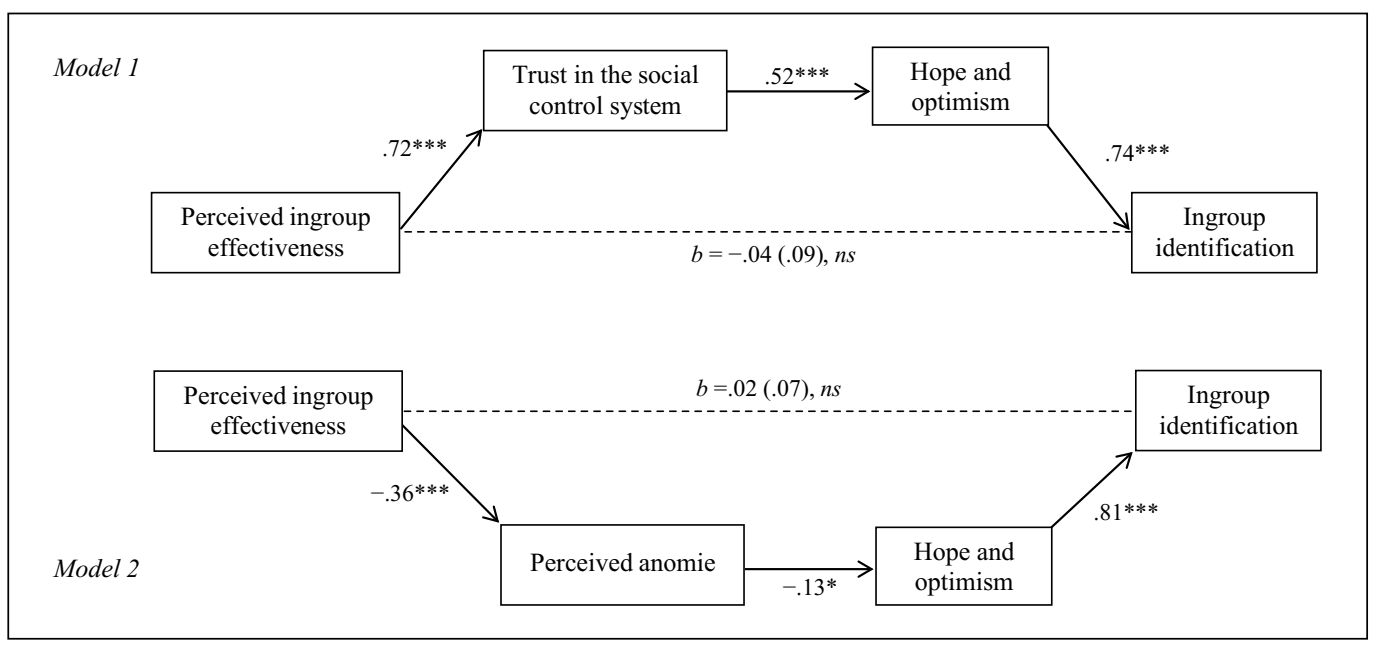

Figure 1. Serial multiple mediation models (1 and 2), with unstandardized effects (Study 3).

Note. $* p \leqslant .05 ; * * p \leqslant .01 ; * * * p \leqslant .001 ; \dagger p \leqslant .10$.

effect: $b=0.36, S E=0.07 ; 95 \% \mathrm{CI}=[0.23,0.50]$; direct effect: $b=0.02, S E=0.07, t<1$.

In brief, these results show that perceived effectiveness predicts ingroup identification to the extent that participants have trust in the group's social control system and perceive a low level of anomie in the group, and, consequently, are hopeful and optimistic about the group. The positive emotional climate seems to be the crucial link between trust in the social control system and perceived low anomie, and commitment to the group.

Mediation analyses involving positive emotions. Regarding positive emotions, we adopted a more exploratory approach. The product-moment correlation analyses allow us to suppose that positive emotions may mediate between perceived effectiveness and both trust in the social control system and perceived anomie. We explored this idea by means of two simple mediation models (PROCESS, Model 4, with 10,000 bootstraps; Hayes, 2013). The mediation analysis using perceived effectiveness as the predictor, positive emotions as the mediator, and trust in the social control system as the dependent variable was significant. The joint effect of perceived effectiveness and positive emotions on trust in the social control system was significant; $F(2,112)=81.03$, $p<.001$. The model accounted for $59 \%$ of the variance; indirect effect: $b=0.18, S E=0.05 ; 95 \%$ $\mathrm{CI}=[0.09,0.29]$; total effect: $b=0.72, S E=0.06$, $t=11.11, p<.001 ; 95 \% \mathrm{CI}=[0.59,0.85] ;$ direct effect: $b=.54, S E=0.07, t=7.46 p<.001 ; 95 \%$ $\mathrm{CI}=[0.40,0.69]$.

We also explored the idea that positive emotions would affect the association between perceived effectiveness and anomie. However the results did not support this idea. In fact, the mediation analysis of perceived effectiveness on anomie using positive emotions as the mediator was not significant. Although the joint effect of perceived effectiveness and positive emotions was significant towards anomie, $F(2,112)=7.79$, $p=.001$ (the model accounted for $12 \%$ of the variance), this effect is mainly due to the direct effect of perceived effectiveness on anomie; indirect effect: $b=0.12, S E=0.07 ; 95 \% \mathrm{CI}=[-0.28$, 0.02]; total effect: $b=-0.36, S E=0.10$, $t=-3.54, p=.001 ; 95 \% \mathrm{CI}=[-0.57,-0.16]$; direct effect: $b=-.25, S E=0.12, t=-2.00$ $p=.048 ; 95 \% \mathrm{CI}=[-0.49,0.00]$.

Together, these results indicate that the more participants perceived the ingroup to be able to react effectively against deviance, the more they were emotionally positive about the ingroup, 
which was associated with trust in the group's social control system. Positive emotions seem to be irrelevant to explain the relationship between ingroup's perceived ineffectiveness and perceived anomie.

Alternative model. In order to ensure that ingroup identification is an outcome (rather than a predictor) of the described process, we compared the results of our predicted models to the results of two alternative models. In the first alternative model, we took ingroup identification as the predictor of hope and optimism via perceived effectiveness and trust in the social control system. In the second alternative model, we took ingroup identification as the predictor of hope and optimism, via perceived effectiveness and anomie. In terms of these models, hope and optimism regarding the ingroup should be a function of ingroup identification as mediated by perception of group effectiveness, trust in the social control system, and perceived anomie. Both alternative models were significant. As regards the first alternative model, the joint effect of ingroup identification, perceived effectiveness, and trust in the social control system on hope and optimism was significant; $F(3,111)=70.06, p<.001$. The model accounted for $65 \%$ of the variance; indirect effect regarding the serial multiple mediator model: $b=0.08, S E=0.03,95 \% \mathrm{CI}=[0.03,0.16]$; total indirect effect: $b=0.20, S E=0.05 ; 95 \% \mathrm{CI}=[0.12$, $0.31]$; direct effect: $b=.47, S E=0.06, t=7.68$, $p<.001 ; 95 \% \mathrm{CI}=[0.35,0.59]$. As regards the second alternative model, the joint effect of ingroup identification, perceived effectiveness, and anomie on hope and optimism was also significant; $F(3$, $111)=62.86, p<.001$. The model accounted for $63 \%$ of the variance; indirect effect regarding the serial multiple mediator model: $b=0.02, S E=0.01$, $95 \% \mathrm{CI}=[0.00,0.05]$; total indirect effect: $b=0.12$, $S E=0.04 ; 95 \% \mathrm{CI}=[0.05,0.21]$; direct effect: $b=$ $0.55, S E=0.06, t=9.50, p<.001 ; 95 \% \mathrm{CI}=[0.44$, $0.67]$. Importantly, however, the greatest amount of variance accounted for by both alternative models comes from the direct effect of ingroup identification on hope and optimism, rather than, as our model predicts, through the serial mediation path.
In our model, in turn, the explained variable is accounted for more by the indirect than by the direct effects. In brief, our proposed model thus endows our assumption that perceived effectiveness is a predictor and not a consequence of ingroup identification with higher statistical reliability.

\section{Discussion}

Perceived group effectiveness affected ingroup identification via positive ingroup emotions, trust in the group's social control institutions, and lower perceived ingroup anomie. This suggests that individuals' belief in the ingroup's ability to effectively respond to deviance is a determinant of their national identification. It is the perception of the ingroup in a positive or negative light that paves the way to higher or lower ingroup identification, respectively, rather than the reverse. In other words, the group's perceived effectiveness thus spurs the positive emotions, collective hope, optimistic expectations, and normative cohesiveness that boost social identification.

\section{Conclusions}

Overall, the results of our three studies consistently support the idea that the ingroup's perceived capability to effectively respond to deviance is an important determinant of members' beliefs and attitudes towards that group. These beliefs and attitudes emerge in terms of ingroup emotions, trust in the group's normative system, and perceived emotional climate of the group. These, in turn affect ingroup identification.

In Study 1, we found that participants to whom it was made salient that the ingroup had not effectively dealt with deviance, perceived higher anomie in, and identified less with, the ingroup than did participants who judged the outgroup. In turn, participants to whom it was made salient that the ingroup had effectively dealt with deviance trusted the group's social control system more, and identified more with it than did participants in the outgroup condition. Results of Study 2 were in line with those of Study 1. 
Participants who learned that the ingroup was ineffective perceived more anomie and identified less with the group than did participants who judged the outgroup. In turn, participants who learned that the ingroup was effective reported more hope and optimism about the ingroup and identified more with it than those who learned that the ingroup was ineffective. In both studies, outgroup effectiveness did not affect participants' beliefs and attitudes.

Consistent with the aforementioned observations, the regression model analyses conducted in Studies 1 and 2 indicate that only in the ingroup condition does effective group reaction predict trust in the social control system (Study 1), and high levels of ingroup identification (Studies 1 and 2). Complementarily, ineffective ingroup reaction predicted perceived anomie (Study 1), negative ingroup, anomic, emotional climate (Study 2), and weaker ingroup identification (Studies 1 and 2). Hope and optimism mediated the negative association between perceived anomie and ingroup identification (Study 2). In line with these findings, the full predicted serial multiple mediator models tested in Study 3 show that belief in the ingroup's effectiveness predicts ingroup identification via the expression of positive ingroup emotions, trust in the group's normative system, (and low perceived anomie), and consequent hope and optimism about the ingroup.

The present results are consistent with, and indeed extend, subjective group dynamics theory and may have important practical implications on their own. They indicate that punishment of ingroup deviants does restore a positive social identity (e.g., Abrams, Marques, Randsley de Moura, Hutchinson, \& Bown, 2004; Marques, Paez, et al., 1998; Pinto et al., 2010), and that this occurs because it spurs trust in and commitment to the ingroup's normative system, leading to optimistic expectations about the group (cf. also Bar-Tal et al., 2007; Swann et al., 2009; Thomas, McGarthy, \& Mavor, 2009). Our studies strongly suggest that by inducing the idea that the group is or is not effective in detecting and punishing ingroup offenders one may boost or sap, respectively, group members' commitment to the standards that underlie their social identity. This should positively or negatively affect group cohesiveness and morale, hence, increasing or decreasing the group's resilience and ability to cope with internal and external strain, and, ultimately, its likelihood of continuing existence in the long run.

Lastly, but no less importantly, our studies were not directly intended as a challenge to the well-established assumption that the more identified individuals are with their group, the stronger is their motivation to exert social pressure on the deviants, and to believe their group does the same, in order to maintain a positive social identity (e.g., Jetten \& Hornsey, 2014; Marques, Paez, et al., 1998; Marques, Yzerbyt, \& Leyens, 1988). However, our results indicate that groups that fail to allow their members to overtly or tacitly engage in prescriptive action against deviance may end up in a state of disruption and anomie. In turn, groups that successfully provide their members with such a possibility may see their members' identity reinforced. In this vein, social identification would not always be a predictor of group attitudes and beliefs but these attitudes and beliefs may also be predictors of social identification.

\section{Acknowledgements}

The authors wish to thank Cícero Pereira for valuable comments on an earlier version of this manuscript.

\section{Funding}

This work is part of project EXCL/MHCPSO/0800/2012, which was supported by the Portuguese Foundation for Science and Technology (FCT). The first author is the principal investigator, and the second and third authors are, respectively, a member of the research team and a consultant on that project.

\section{Notes}

1. Participants were presented with the case of a defendant accused of selling counterfeit driving licenses.

2. In order to make this information more realistic, participants were also informed that "if the charges were proved, suspects would face harsh 
penalties. Among these suspects are the mayor of a small town who is charged with using the towns' workers and machinery for personal profit in the restoration of his country house, the real estate lawyer who allegedly bribed a senior officer of the Ministry of the Environment to allow the construction of a tourist resort inside a protected area, the judge who allegedly conducted a trial of a corporation in which he was a stockholder, or the dean of a public school who presided over a selection board that engaged one of his close relatives to work at the school."

3. Because the anomie scale employed in Study 1 was not directly aimed at the issue of our studies, we employed alternative items that would allow us to more directly tap perception of anomie in Portuguese society as a consequence of social control measures.

\section{References}

Abrams, D., Marques, J. M., Randsley de Moura, G., Hutchinson, P., \& Bown, N. J. (2004). The maintenance of entitativity: A subjective group dynamics approach. In V. Y. Yzerbyt, C. M. Judd, \& O. Corneille (Eds.), The psychology of group perception: Contributions to the study of homogeneity, entitativity, and essentialism (pp. 361-380). Philadelphia, PA: Psychology Press.

Bar-Tal, D., Halperin, E., \& de Rivera, J. (2007). Collective emotions in conflict situations: Societal implications. Journal of Social Issues, 63, 441-460. doi:10.1111/j.1540-4560.2007

Becker, H. S. (1963). Outsiders: Studies in the sociology of deviance. New York, NY: The Free Press.

Ben-Yehuda, N. (1985). Deviance and moral boundaries: Witchcraft, the occult, science fiction, deviant sciences and scientists. Chicago, IL: University of Chicago Press.

Branscombe, N. R., Wann, D. L., Noel, J. G., \& Coleman, J. (1993). In-group or out-group extremity: Importance of the threatened social identity. Personality and Social Psychology Bulletin, 19, 381-388. doi:10.1177/0146167293194003

Carlsmith, K. M. (2006). The roles of retribution and utility in determining punishment. Journal of Experimental Social Psychology, 4, 437-451. doi:10.1016/j. jesp.2005.06.007

Carlsmith, K. M., Darley, J. M., \& Robinson, P. H. (2002). Why do we punish? Deterrence and just deserts as motives for punishment. Journal of Personality and Social Psychology, 83, 284-299. doi:10.1037/0022-3514.83.2.284
Clinard, M. B., \& Meier, R. F. (2004). Sociology of deviant behavior (12th ed.). Belmont, CA: Wadsworth.

Corruption across EU "breathtaking" - EU Commission. (2014). BBC News Europe. Retrieved from http:/ /www.bbc.co.uk/news/world-europe26014387

Davis, C. L., Camp, R. A., \& Coleman, K. M. (2004). The influence of party systems on citizens' perceptions of corruption and electoral response in Latin America. Comparative Political Studies, 37(6), 677-703. doi:10.1177/0010414004265879

De Rivera, J., \& Paez, D. (2007). Emotional climate, human security and culture of peace. Journal of Social Issues, 63, 233-253. doi:10.1111/j.15404560.2007.00506.x

De Sousa, L. (2008). I don't bribe, I just pull strings: Assessing the fluidity of social representations of corruption in Portuguese society. Perspectives on European Politics and Society, 9(1), 8-23. doi:10.1080/15705850701825402

Durkheim, E. (1982). The rules of sociological method. New York, NY: The Free Press. (Original work published 1895)

Durkheim, E. (1997). The division of labor in society. New York, NY: The Free Press. (Original work published 1893)

Erikson, K. (1964). Notes on the sociology of deviance. In H. S. Becker (Ed.), The other side (pp. 9-22). New York, NY: The Free Press.

Fischer, A. H., \& Manstead, A. S. R. (2008). Intergroup emotions. In M. Lewis, J. M. Havilandand, \& L. Feldman (Eds.), Handbook of emotions (3rd ed., pp. 428-439). New York, NY: The Guilford Press.

Fredrickson, B. (2009). Positivity. New York, NY: Crown.

Garland, D. (1996). Social control. In A. Kuper \& J. Kuper (Eds.), The social science encyclopedia (pp. 780-783). London, UK: Routledge.

Gibbs, J. P. (1977). Social control, deterrence, and perspectives on social order. Social Forces, 56, 408423. doi:10.1093/sf/56.2.408

Hamilton, V. L., \& Rauma, D. (1995). Social psychology of deviance and law. In K. S. Cook, G. A. Fine, \& J. S. House (Eds.), Sociological perspectives on social psychology (pp. 524-547). Boston, MA: Allyn \& Bacon.

Harris, A. R., \& Hill, G. D. (1982). The social psychology of deviance: Toward a reconciliation with social structure. Annual Review of Sociology, 8, 161184. doi:10.1146/annurev.so.08.080182.001031 
Hayes, F. (2013).Introduction to mediation, moderation, and conditional process analysis. New York, NY: Guilford Press.

Heidenheimer, A. J. (2002). Perspectives on the perception of corruption. In A. J. Heidenheimer \& M. Johnston (Eds.), Political corruption: Concepts and contexts (pp. 141-154). New Brunswick, NJ: Transaction.

Hogg, M. A., \& Abrams, D. (1988). Social identifications: A social psychology of intergroup relations and group processes. London, UK: Routledge.

Hutchison, P., \& Abrams, D. (2003). Ingroup identification moderates stereotype change in reaction to ingroup deviance. European Journal of Social Psychology, 33, 497-506. doi:10.1002/ejsp.157

Hutchison, P., Abrams, D., Gutierrez, R., \& Viki, G. T. (2008). Getting rid of the bad ones: The relationship between group identification, deviant derogation, and identity maintenance. Journal of Experimental Social Psychology, 44, 874-881. doi:10.1016/j.jesp.2007.09.001

Inverarity, J. (1980). Theories of the political creation of deviance: Legacies of conflict theory, Marx, and Durkheim. In P. Lauderdale (Ed.), A political analysis of deviance (pp. 175-219). Minneapolis: University of Minnesota Press.

Jetten, J., \& Hornsey, M. J. (2014). Deviance and dissent within groups. Annual Review of Psychology, 65, 461485. doi:10.1146/annurev-psych-010213-115151

Levine, J. M. (1989). Reactions to opinion deviance in small groups. In P. B. Paulus (Ed.), Psychology of group influence (pp. 187-231). Hillsdale, NJ: Erlbaum.

Marques, J. M., Abrams, D., Paez, D., \& Taboada, C. (1998). The role of categorization and ingroup norms in judgments of groups and their members. Journal of Personality and Social Psychology, 75, 976-988. doi:10.1037/0022-3514.75.4.976

Marques, J. M., Abrams, D., \& Serôdio, R. (2001). Being better by being right: Subjective group dynamics and derogation of in-group deviants when generic norms are undermined. Journal of Personality and Social Psychology, 81, 436-447. doi:10.1037/00223514.81.3.436

Marques, J. M., \& Paez, D. (1994). The black sheep effect: Social categorisation, rejection of ingroup deviates, and perception of group variability. In W. Stroebe \& M. Hewstone (Eds.), European review of social psychology (Vol. 5, pp. 38-68). New York, NY: Wiley.

Marques, J. M., Paez, D., \& Abrams, D. (1998). Social identity and intra-group perception. In J. F. Morales, D. Paez, J. C. Deschamps, \& S. Worchel
(Eds.), Current perspectives on social identity and social categorization (pp. 124-141). New York, NY: Sage.

Marques, J. M., Robalo, M., \& Rocha, S. A. (1992). Ingroup bias and the black sheep effect: Assessing the impact of cognitive-motivational and informational antecedents of judgemental extremity towards ingroup members. European Journal of Social Psychology, 22, 331-352. doi:10.1002/ejsp.2420220403

Marques, J. M., Yzerbyt, V. Y., \& Leyens, J.-P. (1988). The black sheep effect: Judgmental extremity towards ingroup members as a function of ingroup identification. European Journal of Social Psychology, 18, 1-16. doi:10.1002/ejsp.2420180102

Merton, R. (1938). Social structure and anomie. New York, NY: Irvington.

Merton, R. (1968). Social theory and social structure. New York, NY: Free Press.

O’Mara, E. M., Jackson, L. E., Batson, D., \& Gaertner, L. (2011). Will moral outrage stand up? Distinguishing among emotional reactions to a moral violation. European Journal of Social Psychology, 41, 173-179. doi:10.1002/ejsp.754

Orcutt, J. D. (1973). Societal reaction and the reaction to deviation in small groups. Social Forces, 52, 259 267. doi: $10.2307 / 2576380$

Paez, D., Espinosa, A., \& Bobowik, M. (2013). Emotional climate: How is it shaped, fostered, and changed? In D. Hermans, B. Rimé, \& B. Mesquita (Eds.), Changing emotions (pp. 113-119). London, UK: Psychology Press.

Paez, D., \& Rimé, B. (2014). Collective emotional gatherings: Their impact upon identity fusion, shared beliefs and social integration. In M. Salmela \& C. von Scheve (Eds.), Collective emotions (pp. 204 216). Oxford, UK: Oxford University Press.

Pinto, I. R., Marques, J. M., Levine, J. M., \& Abrams, D. (2010). Membership status and subjective group dynamics: Who triggers the black sheep effect? Journal of Personality and Social Psychology, 99, 107-119. doi:10.1037/a0018187

Poeschl, G., \& Ribeiro, R. (in press). Everyday opinions on grand and petty corruption: A Portuguese study. In A. Teixeira, C. Pimenta, A. Maia, \& J. A. Moreira (Eds.), Corruption, economic growth and globalization. London, UK: Routledge.

Prentice, D. A., Miller, D. T., \& Lightdale, J. R. (1994). Asymmetries in attachments to groups and their members: Distinguishing between common-identity and common-bond groups. Personality and Social Psychology Bulletin, 20, 484-493. doi:10.1177/0146167294205005 
Rosenthal, R., Rosnow, R. L., \& Rubin, D. B. (2000). Contrasts and effect sizes in behavioral research: $A$ correlational approach. Cambridge, UK: Cambridge University Press.

Seeman, M. (1991). Alienation and anomie. In J. P. Robinson, P. R. Shaver, \& L. S. Wrightsman (Eds.), Measures of personality and social psychological attitudes (pp. 291-371). San Diego, CA: Academic Press.

Simmel, G. (1955). Conflict and the web of group affiliations. New York, NY: The Free Press.

Swann, W. B., Jr., Gómez, Á., Seyle, D. C., Morales, J. F., \& Huici, C. (2009). Identity fusion: The interplay of personal and social identities in extreme group behavior. Journal of Personality and Social Psychology, 96, 995-1011. doi:10.1037/a0013668

Tajfel, H. (1978). Interindividual behaviour and intergroup behaviour. In H. Tajfel (Ed.), Differentiation between social groups: Studies in the social psychology of intergroup relations (pp. 27-60). London, UK: Academic Press.
Tangney, J., Stuewig, J., \& Mashek, D. (2007). Moral emotions and moral behavior. Annual Review of Psychology, 58, 345-372. doi:10.1146/annurev. psych.56.091103.070145

Thomas, E. F., McGarthy, C., \& Mavor, K. I. (2009). Aligning identities, emotions and beliefs to create commitment to sustainable social and political action. Personality and Social Psychology Bulletin, 13, 194-218. doi:10.1177/1088868309341563

Turner, J. C. (1975). Social comparison and social identity: Some prospects for intergroup behaviour. European Journal of Social Psychology, 5(1), 1-34. doi:10.1002/ejsp.2420050102

Turner, J. C. (1981). The experimental social psychology of intergroup behaviour. In J. C. Turner \& H. Giles (Eds.), Intergroup behaviour (pp. 66-101). Oxford, UK: Blackwell.

Turner, J. C., Hogg, M. A., Oakes, P. J., Reicher, S. D., \& Wetherell, M. S. (1987). Rediscovering the social group: A self-categorization theory. Oxford, UK: Blackwell. 